\title{
Escola e Psicologia: Uma História de Encontros e Desencontros
}

\author{
Lisiane Machado de Oliveira-Menegotto \\ Universidade Feevale - Novo Hamburgo - RS \\ Gabriela Prado da Fontoura \\ Prefeitura Municipal de Parobé - Parobé - RS
}

\begin{abstract}
Resumo
O presente artigo propõe-se a discutir os encontros e desencontros entre a Psicologia e a Escola, problematizando a heterogeneidade de posições acerca do fracasso escolar. Foi realizada uma revisão de artigos científicos na base SciELO, utilizando o descritor "Psicologia Escolar". Foram selecionados 32 artigos publicados a partir de 2003, que tratavam de estudos no contexto brasileiro e que faziam uma discussão sobre a inserção da Psicologia na Escola. A leitura minuciosa e a análise dos artigos originaram três eixos de discussão: A inserção da Psicologia na Escola: ideologias em comum; Resistências e tensionamentos: o nascimento do desencontro entre a Psicologia e a Escola; e Perspectivas em pauta: uma abordagem que considera a constelação escolar. A discussão evidenciou que a Psicologia foi introduzida na Escola por meio de um modelo médico/clínico, responsabilizando o aluno pelo fracasso escolar. A superação desse modelo ocorreu na medida em que esse fenômeno passou a considerar outras implicações.
\end{abstract}

Palavras-chave: Psicologia Escolar; Psicologia Educacional; História da Psicologia

\section{School and Psychology: A History of Convergences and Divergences}

\begin{abstract}
This article proposes to discuss the similarities and differences between Psychology and the School, discussing the heterogeneity of positions on the school failure. A review of scientific literature was conducted in SciELO, using the "Educational Psychology" descriptor. We selected 32 articles published since 2003, which dealt with studies in the Brazilian context and that made a discussion on the introduction of Psychology in the School. A close reading and analysis of articles originated three areas of discussion: The introduction of Psychology in School: common ideologies; Resistances and tensions: the birth of the mismatch between Psychology and the School; and Perspectives on the agenda: an approach that considers the school constellation. The discussion showed that psychology was introduced in the School by passing a medical / clinical model, blaming the student for school failure. Overcoming this model occurred in that this phenomenon started to consider other implications.
\end{abstract}

Keywords: School Psychology; Educational Psychology; History of Psychology

\section{Escuela y Psicología: Una Historia de Encuentros y Desencuentros}

\section{Resumen}

El presente artículo se propone a discutir los encuentros y desencuentros entre la Psicología y la Escuela, problematizando la heterogeneidad de posiciones acerca del fracaso escolar. Se realizó una revisión de artículos científicos en la base SciELO, utilizándose el descriptor "Psicología Escolar". Se seleccionó 32 artículos publicados a partir de 2003, que trataban de estudios en el contexto brasileño y que hacían una discusión sobre la inserción de la Psicología en la Escuela. La lectura minuciosa y el análisis de los artículos originaron tres ejes de discusión: La inserción de la Psicología en la Escuela: ideologías en común; Resistencias y tensionamientos: el nacimiento del desencuentro entre la Psicología y la Escuela; y Perspectivas en pauta: un abordaje que considera la constelación escolar. La discusión evidenció que la Psicología fue introducida en la Escuela por medio de un modelo médico/clínico, responsabilizando el alumno por el fracaso escolar. La superación de ese modelo ocurrió en la medida en que ese fenómeno pasó a considerar otras implicaciones.

Palabras clave: Psicología Escolar; Psicología Educacional; Historia de la Psicología. 


\section{Introdução}

Na medida em que o tempo dimana e a sociedade se transforma, as concepções acerca da educação se alteram sofrendo influências ideológicas do momento histórico que se faz presente. A escola, como espaço legitimado de educação formal, tem se deparado, ao longo dos tempos, com inúmeros desafios que requerem um olhar para além do já garantido pelos profissionais da Educação. É nessa abertura que a Psicologia entra no ambiente escolar, possibilitando diálogos e articulações com a Educação.

Diante da importância de retomar a história da Psicologia Escolar e de problematizar a heterogeneidade de posições acerca do fracasso escolar, este artigo tem por objetivo discutir os encontros e desencontros entre a Psicologia e a Escola, problematizando seus impasses e seus desafios. Para tanto, foi realizada uma revisão de artigos científicos na base SciELO - Scientific Electronic Library Online, utilizando a expressão "Psicologia Escolar" como descritor. Foram encontrados 68 artigos. Desse contingente, ponderamos somente aqueles que foram publicados no período de 10 anos, considerando o intervalo entre 2003 e 2013, e que tratavam de estudos no contexto brasileiro. Após a leitura dos artigos foram selecionados apenas os que propunham uma discussão sobre a inserção da Psicologia na Escola, totalizando 32 publicações. Foi feita uma leitura minuciosa e dirigida dos 32 artigos, a partir do foco da relação entre a Psicologia e a Escola. A análise consistiu em elencar os temas que foram mais representativos da relação entre a Psicologia e a Escola ao longo da história. Por fim, os temas foram organizados em três eixos, que serão objeto de discussão no presente artigo: 1) A inserção da Psicologia na Escola: ideologias em comum; 2) Resistências e tensionamentos: o nascimento do desencontro entre a Psicologia e a Escola; e 3) Perspectivas em pauta: uma abordagem que considera a constelação escolar.

Este estudo pode auxiliar no entendimento da atuação profissional da Psicologia na escola, além de colaborar para uma melhor relação entre teoria e prática, tornando-se fonte importante para o estudo da identidade e do compromisso social da Psicologia Escolar. Assim, podemos gerar elementos para uma reflexão da história que vem sendo (re) produzida no que se refere às queixas escolares.

\section{A Inserção da Psicologia na Escola: Ideologias em Comum}

O presente eixo pretende discutir o encontro entre a Psicologia e a Escola, uma vez que ambas partem de ideologias semelhantes, inscritas na história da Escola e da Psicologia. Assim, retomando a história, cabe considerar que Escola e Psicologia se aproximam por meio de um pacto pautado numa perspectiva que simplifica o fracasso escolar, tomando-o a partir de uma causalidade linear.

Os jesuítas chegaram ao Brasil em meados do século XVI, com a missão de colonizar os povos originários.
Assim, o ensino consistia em formar um padrão de homem que pudesse ser moldado, civilizado. Isso aconteceu por meio da instrução, conforme a concepção de civilização dos jesuítas. Nessa perspectiva, a educação nasceu com uma forte associação com o controle e com a domesticação, que ocorriam, muitas vezes, por meio dos castigos físicos (Barbosa, 2012). Os reflexos disso podem ser vistos, ao longo da história da escola, no uso da palmatória como símbolo de disciplina, baseada na ideia de correção de comportamentos. Atualmente, a palmatória está em desuso, mas a escola ainda se vê impregnada pela ideia da correção e da domesticação dos corpos, por meio da disciplina. Nessa mesma perspectiva, o currículo,assim como a organização dos espaços e dos tempos que fazem parte do cotidiano escolar, pode ser considerado uma forma de controle exercido no espaço escolar.

A missão da Companhia de Jesus era a de catequizar, tornando os índios mais dóceis e submissos, a fim de adaptá-los como mão de obra. Assim, devido ao trabalho dos jesuítas, o Brasil permaneceu e talvez ainda permaneça, por muito tempo, com uma educação de caráter disciplinador, adaptacionista e excludente (Barbosa, 2012), apesar do advento das políticas inclusivas no campo educacional.

A escola, portanto, nasce fortemente influenciada por tal posição ideológica de controle e de domesticação dos corpos e o seu encontro com a Psicologia ocorre a partir de ideologias semelhantes, já que a Psicologia, a partir de uma tradição positivista (Fontes, \& Lima, 2011; Soares, \& Araújo, 2010; Yamamoto, Santos, Galafassi, Pasqualini, \& Souza, 2013), insere-se na escola avaliando e diagnosticando os alunos, utilizando-se de instrumentos e laudos baseados em pressupostos científicos. Nessa perspectiva, dentre a minoria, representada pela elite brasileira, aqueles que eram considerados inaptos, invariavelmente, eram excluídos do sistema educacional. Assim, a entrada da Psicologia no campo escolar ocorreu na medida em que ela respondeu à demanda de avaliação, diagnóstico, classificação e tratamento dos alunos (Silva, \& Mendes, 2012), psicologizando e patologizando a queixa escolar (Nakamura, Lima, Tada, \& Junqueira, 2008). Para isso, a Psicologia adaptou as ferramentas da clínica para a escola.

Como apontam Barbosa e Souza (2012), a Psicologia Educacional no Brasil impregnou-se dos princípios do movimento higienista, no início até meados do século $X X$, tendo como propósito diferenciar os sujeitos mentalmente saudáveis daqueles que não o eram, legitimando o psicólogo, por possuir condições de manejar instrumentos científicos restritos ao seu campo, a diferenciar os sujeitos aptos dos não aptos. Tal perspectiva da Psicologia era eminentemente clínica e de caráter individual, e servia aos propósitos de ajustamento e de classificação, não levando em consideração a crítica e a compreensão social (Silva, Pedro, Silva, Rezende, \& Barbosa, 2013; Wanderer, \& Pedroza, 2010). O social, por sua vez, era somente levado em consideração, na medida em que a preocupação girava em torno de normalizar e adaptar o sujeito para o convívio em sociedade 
(Angelucci, Kalmus, Paparelli, \& Patto, 2004; Barbosa, 2012; Tuleski, \& cols., 2005).

A Psicologia também foi inserida na escola através de suas teorias sobre o desenvolvimento das crianças e dos adolescentes. Tais teorias eram formuladas a partir de concepções ideológicas de repressão e controle de tendências espontâneas, sem questionar a dinâmica da instituição de ensino. Assim, ambas, a Psicologia e a Educação, uniram-se para atender à ideologia segregadora e excludente vigente desde o advento da escola no Brasil (Guzzo, Mezzalira, Moreira, Tizzei, \& Silva Neto, 2010). Afinal, a escola nunca fora para todos. Com o auxílio da Psicologia, buscava-se atender somente uma minoria, considerada capaz de passar pelo processo de escolarização. Desse princípio resultou o aparecimento das escolas e classes especiais (Valle, 2003).

O encontro entre a Psicologia e a Escola ganha força, na medida em que ambas compartilham da mesma ideologia. Assim, a Psicologia auxiliou a Escola na manutenção de regras, contribuindo para gerar disciplina e controle, e a Escola abriu caminhos para a atuação da Psicologia, por se constituir como um espaço privilegiado para a aplicação de seus instrumentos científicos (Barbosa, 2012). Nessa perspectiva, disciplina e controle não eram somente práticas que exerciam restrições aos sujeitos a partir de regras ou de processos que levam ao medo, como o autoritarismo, e sim também práticas que fazem parte do sistema de ensino, tais como fila, uniforme, segregação de classes, idade, sexo.

Por meio do manejo dos instrumentos o psicólogo consolidava seu lugar na escola, justificado pelo projeto de transformação e modernização do Brasil, uma vez que o crescimento do país, nessa lógica, dependia da moralização e da higienização. Assim, práticas excludentes tornaram-se naturalizadas, de modo que aqueles que eram enquadrados como inaptos ou anormais e, portanto, não se adaptavam ao modelo de desenvolvimento pretendido, eram apartados do espaço escolar e tornavam-se objeto de interesse da Psicologia. Eles foram nomeados de diferentes modos ao longo dos tempos: débil, retardado, criança-problema, alunoproblema, alunos fracassos, indisciplinados etc. A ideia era identificá-los e discriminá-los como "diferentes" (Barbosa, \& Souza, 2012).

A Psicologia, dessa forma, se insere na instituição de ensino utilizando-se de práticas clínicas (Lessa, \& Facci, 2011), de caráter individual e segregador, na medida em que desconsiderava o fracasso escolar como produto da instituição (Cunha, \& Betini, 2003). Consolida-se, nesse sentido, um encontro entre os métodos psicológicos e educativos, validados diante da prática da clínica psicológica na escola (Guzzo, \& cols., 2010). Para a Psicologia, cabia a responsabilidade de atender aos anseios da escola de "consertar" os alunos, buscando "corrigi-los", de maneira que retornassem para a sala de aula, quando possível, sem perturbar o andamento da aula. A escola demandava-lhe curar o aluno-problema e devolvê-lo sadio.

Nesse cenário, a escola mantinha um gabinete de Psicologia, para onde eram encaminhados os alunos considerados problemas, a fim de avaliá-los, tratá-los e curá-los
(Martins, 2003). Teorias oriundas do campo da clínica eram utilizadas na escola, caracterizando uma prática clínico-terapêutica na educação (Dazzani, 2010). Entretanto, um dos maiores impasses decorrentes dessa prática é que os aspectos sociais, culturais, históricos e institucionais não eram levados em consideração no trabalho do psicólogo. Era-lhe demandada apenas a correção do indivíduo, para que este pudesse se adaptar ao sistema (Cavalcante, \& Aquino, 2013). Aqueles que não conseguiam encaixar-se ao sistema eram, invariavelmente, excluídos, estigmatizados e discriminados.

Conforme Barbosa (2012), a área, ainda chamada de Psicologia Educacional, foi se estabelecendo por meio de um olhar para a criança que não aprende. Em se tratando dos processos educativos, houve o uso de testagem e classificação das crianças, com o intuito de conhecer suas habilidades e problemas dos alunos. Assim sendo, crianças cujas dificuldades de aprendizagem eram confirmadas pelas avaliações psicológicas eram encaminhadas para tratamento, conduzido pela Psicologia Clínica (Sant'Ana, Euzébios Filho, Lacerda Junior, \& Guzzo, 2009).

Portanto, a concepção que norteava o trabalho da Psicologia no contexto escolar era de mensurar a capacidade intelectual dos alunos (Martins, 2003; Tondin, Dedonatti, \& Bonamigo, 2010; Vokoy, \& Pedroza, 2005; Wanderer, \& Pedroza, 2010), a fim de separar os aptos dos não aptos para a aprendizagem, caracterizando um pensamento excludente, moderno e linear, ou seja, de causa e efeito. Tal avaliação gerava um diagnóstico e um laudo, que tinham o poder de retirar o aluno da sala para, na medida do possível, readaptá-lo, para corrigi-lo. Assim, todo o fracasso era centrado no aluno. O caráter das explicações acerca do fracasso escolar era reducionista, centrando-se no aluno (Andrada, 2005). Em decorrência dessa concepção, surgiram inúmeras hipóteses que justificavam o fracasso escolar: famílias desestruturadas, preguiça, indisciplina, incapacidade intelectual, carência afetiva, hiperatividade, entre outros.

Havia, na base dessa relação entre a Psicologia e a Escola, a concepção higienista, o que justificava a identificação, a seleção e a classificação das crianças (Barbosa, 2012; Tondin, \& cols., 2010). À Psicologia cabia agir, por meio de um modelo clínico-terapêutico, fora da sala de aula. Assim, focava sua atenção na dimensão individual do educando e em seus «problemas», atendendo, sobretudo, demandas específicas da escola, que encaminhava as crianças que tinham, a seu ver, problemas de aprendizagem ou outras manifestações consideradas como distúrbios inerentes ao próprio educando (Lessa, \& Facci, 2011).

Como visto acima, a entrada da Psicologia na Escola inicialmente serviu à seleção e à adaptação dos alunos ao modelo social da época. Sua atuação cumpria com uma missão ideológica de manutenção do status quo (Chagas, \& Pedroza, 2013). Para dar conta dessa proposta, o trabalho da Psicologia Escolar adotou uma concepção individualista do fracasso escolar (Soares, \& Araujo, 2010), calcada na dicotomia saúde e doença (Chagas, \& Pedroza, 2013). Assim, as primeiras aproximações entre a Psicologia e a 
Escola estavam pautadas numa visão associacionista e mecanicista, a partir de ideias deterministas e dicotômicas acerca da aprendizagem e do desenvolvimento humano. Diante disso, instalou-se na escola uma concepção causal e reducionista acerca das queixas escolares, de modo que ora o aluno, ora o ambiente social, era responsabilizado pelo fracasso escolar (Soares, \& Araujo, 2010).Entretanto, resistências e tensionamentos começaram a emergir na relação entre a Psicologia e a Escola, no sentido de superar a lógica classificatória e segregacionista oriunda do modelo clínico (Chagas, \& Pedroza, 2013).

\section{Resistências e Tensionamentos: O Nascimento do Desencontro entre a Psicologia e a Escola}

Este eixo propõe-se a discutir as resistências e os tensionamentos que começam a surgir na relação entre a Psicologia e a Escola. Tal desencontro nasceu do questionamento acerca da prática reducionista da Psicologia no contexto escolar, marcada por uma abordagem linear do fracasso escolar, cuja responsabilidade pesava sobre o aluno e, por extensão, a sua família.

Considerando o percurso histórico, em 1962 é criada a profissão de psicólogo no Brasil, e a Psicologia, em sua relação com a Escola, continuou o seu trabalho de classificar, orientar e tratar de crianças-problema. A tradição médica e o foco individual de orientação continuavam tendo força. Nesse período, os laudos de crianças em idade escolar eram frequentemente elaborados para encaminhamentos às chamadas escolas especiais e depois às classes especiais (Barbosa, 2012; Barbosa,\& Souza, 2012). Entretanto, é na década de 1970 que tal tendência reducionista passa a sofrer críticas de pedagogos e psicólogos. Criticavam-se a utilização dos testes e a interpretação de seus resultados, que atribuía somente ao aluno e a sua família a determinação de seus problemas, tornando irrelevantes os processos educativos como um todo. O olhar patologizante, por meio de interpretações e ações baseadas em conhecimentos disseminados pela Psicologia da época, por educadores e psicólogos, também foi colocado em xeque, uma vez que,a partir de uma visão inatista,os determinantes da aprendizagemde natureza social, cultural, econômica e, sobretudo, pedagógica eram tomados como irrelevantes. Nessa perspectiva, era atribuída ao sujeito a responsabilidade pelo fracasso escolar, tendo como consequências, a patologização e biologização dos problemas de aprendizagem, o que reforçava ainda mais a exclusão de alunos das classes menos privilegiadas da escola (Asbahr, Martins, \& Mazzolini, 2011).

Mesmo que a Psicologia tenha se caracterizado, inicialmente, como ciência comprometida com a ordem e o controle, cuja concepção de diferenciar os aptos dos não aptos para a aprendizagem desconsiderava a dimensão social (Andrada, 2005; Tondin, \& cols., 2010; Tuleski, \& cols., 2005), uma nova percepção sobre o aluno se constituía. Surgiram, assim, críticas aos modelos autoritários e lineares que estavam sendo utilizados pela Psicologia Escolar (Gion- go, \& Oliveira-Menegotto, 2010). Não bastava responsabilizar somente as crianças e suas famílias, para justificar o desempenho do aluno na escola, desconsiderando os fatores de natureza histórica, social, cultural, política, econômica e, sobretudo, pedagógica (Soares, \& Araújo, 2010). As críticas foram um passo importante para o processo de reformulação do objeto de estudo e intervenção da Psicologia Escolar, bem como sua metodologia (Fontes, \& Lima, 2011).

Autores como Bassani e Pinel (2011), Cavalcante e Aquino (2013) e Ramos (2011) apontam que tais críticas voltadas ao trabalho do psicólogo escolar foram materializadas na tese de doutorado Maria Helena Souza Patto (1981b), cujas contribuições representam um marco no que se refere ao questionamento e à resistência ao modelo médico/ clínico da Psicologia Escolar. A proposta de Patto era a de abandonar a atuação clínica e constituir novas formas de compreensão do fracasso escolar, dando lugar a um debate crítico acerca da identidade e a função do psicólogo escolar.

A crítica materializada nos trabalhos de Patto (1981a, 1981b, 1987) produziu um jogo de resistências e tensionamentos entre a Psicologia e a Escola. De um lado, a Escola estava acompanhando os avanços nas discussões sobre as queixas escolares, mas sua prática ainda estava impregnada do discurso do aluno-problema, e, de outro, a Psicologia estava revendo sua identidade no contexto escolar e assumindo uma perspectiva social nos campos da teoria e da prática. Isso produziu um desencontro, nomeado por autores como crise (Andrada, 2005) e ruptura (Angelucci, \& cols., 2004).

O pensamento de Vygotsky foi apontado por Andrada (2005, p.197) como um dos disparadores da "crise da psicologia" no contexto escolar, por ser um pensador que atribuiu significativa importância do contexto social na leitura dos processos psíquicos do indivíduo. Isso engendrou mudanças no olhar sobre o ensino e a aprendizagem, de modo a abandonar a concepção de que o aluno é o problema, apartado do seu contexto de relações.

Angelucci e cols.(2004) assinalaram uma ruptura entre a Psicologia e a Escola, produzida por fatores que passam a ser levados em conta na reflexão sobre o fracasso escolar, tais como os fatores históricos e sociais da Educação e da Escola. Assim, atribuem aos estudos de Althusser sobre ideologias do estado a importância de se firmar a concepção de que a Escola é uma instituição social que deve ser compreendida a partir da estrutura da sociedade. Nesse sentido, de um lado se mantém na Escola um discurso que psicologiza o fracasso escolar e de outro as influências ideológicas histórico-sociais, calcadas na concepção de uma sociedade dividida em classes, de modo a ressignificar o fracasso escolar como produzido pela escola.

O desencontro ocorre a partir do momento em que a Psicologia passa a tecer uma crítica ao contexto escolar, considerando o fenômeno educacional como produto da relação que se estabelece na Escola, que também se vê atravessada pelas políticas educacionais e pela história que a compõe. Tal problematização é fortemente marcada pelo trabalho de Maria Helena Souza Patto (1981a), que redimensiona a concepção vigente do atendimento à queixa escolar, deslocando 
o eixo da Psicologia Clínica para o da Psicologia Social e adotando modelos teórico-metodológicos que não respondessem à demanda adaptacionista da escola (Souza, 2009).

A Psicologia, antes caracterizada como uma ciência comprometida com a ordem e o controle, sem valorizar o contexto histórico e social dos alunos (Tuleski, \& cols., 2005), passa a construir uma nova percepção do sujeito como agente transformador. Assim, a ideia remediativa e classificatória cede lugar à ressignificação da prática profissional (Barbosa, \& Marinho-Araújo, 2010). Diante disso, a Psicologia precisou consolidar novas práticas dentro da Escola, adotando uma prática sistêmica, que considera que o fracasso escolar está para além do indivíduo, de modo que as intervenções tenham como base a visão institucional, reconhecendo que o fracasso escolar não está polarizado nem no professor e nem no aluno, mas sim num sistema de relações (Giongo, \& Oliveira-Menegotto, 2010).

É colocado em questionamento o caráter remediador e terapêutico da prática da Psicologia na Escola, caracterizada por objetivos adaptativos. A visão social passa a ser articulada com a Psicologia, reconhecendo a escola como um espaço plural e de práticas interdisciplinares. Nesse sentido, o fenômeno passa a ser considerado como multideterminado, de modo que as queixas escolares são tomadas a partir de uma "ordem institucional e social onde a criança vive, e não um problema exclusivo da própria criança" (Dazzani, 2010, p.373).

Dito de outra forma, resistências e tensionamentos entre a Psicologia e a Escola começaram a surgir, a partir do momento em que a Psicologia que, até então, colaborava para a produção e reforçava a identidade da criança-fracasso, passou a adotar um olhar social do fenômeno subjetivo (Tuleski, \& cols., 2005). O problema é que a Escola ainda se mantinha fiel à concepção adaptacionista e reducionista do fenômeno educativo.

Assim sendo, o avanço mais significativo da Psicologia como ciência e como profissão foi perceber a Escola e os problemas ali presentes a partir de outro paradigma, o que exigiu o abandono do modelo da causalidade linear e reducionista (Valle, 2003). O novo paradigma assumiu uma visão sistêmica do fenômeno do fracasso escolar e, portanto, de causalidade circular; paradigma baseado na cibernética, na teoria geral dos sistemas e na teoria da comunicação, que se baseia na reflexão contextual e na impossibilidade da observação neutra, cujos princípios são: totalidade, integridade de subsistemas e circularidade (Andrada, 2005). O aluno passa a ser visto como um aspecto na trama das relações que fazem parte do campo da Escola. Dessa forma, o sujeito é visto na sua totalidade e o erro não é mais tomado pelo viés patológico e sim como um processo inerente ao aprendizado (Valle, 2003). Tal processo cede lugar a novas perspectivas da Psicologia Escolar, atreladas a novas concepções e formas de intervenção no campo escolar. Afinal, a ressignificação do fracasso escolar exige da Psicologia um repensar acerca da sua prática na Escola, de modo que resistências e tensionamentos cedam lugar a uma abordagem que aponte para possibilidades de encontro.

\section{Perspectivas Em Pauta: Uma Abordagem que Considera a Constelação Escolar}

O presente eixo apresenta uma discussão sobre o lugar que a Psicologia Escolar assumiu na sua relação com o fracasso escolar, considerando o trabalho pioneiro de Maria Helena Souza Patto (1981a, 1981b, 1987), especialmente as contribuições oriundas de sua tese de doutorado (Patto, 1981b), quando apresenta uma importante crítica à Psicologia comprometida com a dominação, na medida em que atribui os problemas escolares a deficiências naturais da criança. Tal crítica se dirige à abordagem fundamentada na Teoria da Carência Cultural, que culpabiliza as deficiências ambientais, conforme uma concepção naturalizada da sociedade, e que parte da lógica de que as crianças oriundas de classes populares têm atraso cognitivo.

$\mathrm{Na}$ antiguidade, os astrônomos imaginavam que diante do agrupamento das estrelas poderíamos ver imagens; imagens de qualquer coisa. Essas imagens nos ajudariam a perceber a imensidão da infinidade do céu em partes menores. Na verdade, aqui não importam somente as imagens, mas as estrelas e suas constelações.

Reportando essa lógica às escolas, na atualidade os profissionais imaginam que diante do agrupamento de alunos podemos ver problemas; problemas de qualquer ordem. Esses problemas nos ajudariam a perceber a imensidão do fracasso educacional em responsabilidades menores. $\mathrm{Na}$ verdade, aqui não importam somente os problemas; importam os alunos, a Escola e todo o contexto.

Estrela ou aluno, céu ou escola, ambos são dignos de apreciação, pelos fenômenos que produzem e pelas responsabilidades que cultivam. Não se trata, portanto, de ver só o aluno ou só o professor ou só a família. É preciso entender a dinâmica entre eles.

Como mecanismo de resistência, a Escola ainda se mantém funcionando com significativos vestígios da tradição médica e higienista, utilizando-se de mecanismos de disciplinamento. Ainda há um hiato entre as produções científicas no campo da Educação e a prática pedagógica. No campo da Psicologia, paradoxos como esse também podem ser identificados. Assim, embora a atuação do psicólogo escolar tenha sofrido críticas, muitas vezes a sua atuação ainda se vê impregnada pela concepção do fracasso escolar desde uma perspectiva excludente e linear (Andrada, 2005). Apesar de apresentar uma "nova roupagem", o fracasso escolar ainda é considerado como produto do aluno e de sua família (Bassani, \& Pinel, 2011, p. 552; Cavalcante, \& Aquino, 2013). O maior efeito disso pode ser visto na concepção medicalizadora da educação (Bassani, \& Pinel, 2011; Yamamoto, $\&$ cols., 2013). Não é raro nos depararmos com um apelo patologizador e medicalizador naqueles que trabalham diretamente com os alunos. A Psicologia, por muito tempo, correspondeu a tal demanda, inserindo-se na escola com tal visão reducionista do fracasso escolar.

A formação acadêmica do psicólogo pode ser uma das causas da impregnação clínica e psicopatológica da Psicologia Escolar (Tada, Sápia, \& Lima, 2010). Os cursos de 
Psicologia no Brasil ainda apresentam forte atravessamento da clínica e do tratamento da doença, a partir do olhar médico e psicopatológico. Sendo assim, as demais áreas da Psicologia, incluindo a Psicologia Escolar, consolidaramse a partir de "uma histórica luta e resistência ao impacto da ideologia sobre a prática profissional vigente" (Guzzo, \& cols., 2010, p.139).

A formação pautada em discussões políticas e em práticas dirigidas à crítica e à construção da profissão pode ser uma alternativa, no sentido de mudar o cenário de atuação do psicólogo, de modo que o profissional venha a assumir o compromisso de trabalhar com os problemas sociais (Guzzo, Mezzalira, \& Moreira, 2012; Silva, \& cols., 2013). Por isso, é necessária uma revisão na formação acadêmica, aprofundando discussões teóricas e práticas, a fim de prepará-lo para atuar, considerando as múltiplas facetas da Psicologia como ciência e como profissão. Tal formação deve estar orientada pela concepção de uma sociedade menos excludente e da busca de um espaço escolar plural de respeito à cidadania (Cunha, \& Betini, 2003).

Ainda acerca da visão linear e reducionista impregnada na prática da Psicologia Escolar, é importante lembrar que a resolução do Conselho Federal de Psicologia Nº2/01, que apresenta as possibilidades de atuação do psicólogo escolar no sentido de guiar intervenções que considerem todos os segmentos do sistema educacional que participam do processo de ensino-aprendizagem, ainda é recente, considerando a história da Psicologia e sua relação com a escola. Tal documento traz uma reflexão sobre a atuação da Psicologia Escolar, compreendendo todos os protagonistas da escola e um trabalho de caráter interdisciplinar.

Superar o paradigma antigo é fundamental, uma vez que o fenômeno do fracasso escolar carrega uma complexidade de determinações (Asbahr, \& Lopes, 2006). Trata-se de não focar somente em uma estrela e sim na constelação. Para tanto, é preciso abandonar o fazer clínico na escola, propondo uma atuação na Instituição de Ensino como um todo e não somente no aluno como sujeito a ser (re)adequado ao meio social (Giongo, \& Oliveira-Menegotto, 2010). Não se trata de culpabilizar alguém pelo fracasso escolar e sim de comprometer todos os envolvidos na cena do ensino-aprendizagem. É preciso romper com a visão linear e assumir uma visão sistêmica do fenômeno. É preciso que o psicólogo escolar não se pergunte sobre o motivo pelo qual a criança não aprende e sim sobre o que ocorre no processo que faz com que ela não aprenda. É necessário integrar práticas que possibilitem entender os problemas desde uma perspectiva diferenciada, compreendendo as dificuldades de aprendizagem como manifestações inerentes ao aluno e à dinâmica de funcionamento da escola e da sociedade (Giongo, \& Oliveira-Menegotto, 2010).

Nessa perspectiva, é necessário "resistir ao consultório particular, ao modelo médico de compreensão do fracasso escolar, aos elementos ideológicos presentes no corpo de conhecimento da Psicologia" (Guzzo, \& cols., 2010, p.139). É necessário construir novas formas de pensar e integrar-se à equipe pedagógica, desconstruindo as marcas históricas deixadas pelas práticas excludentes da Psicologia Escolar (Giongo, \& Oliveira-Menegotto, 2010).

A ressignificação da atuação da Psicologia Escolar engendrada, sobretudo, pelos estudos iniciais de Patto (1981a, 1981b, 1987), gerou um crescimento de produções científicas relacionadas a vários temas da Psicologia Educacional e Escolar. É a partir de então que passam a surgir publicações como livros, artigos, teses, dissertações e informativos diversos com temáticas variadas sobre a área, ampliando, por sua vez, o espectro de análise e discussão acerca da prática da Psicologia na escola. O caráter individualista da Psicologia Escolar passa a ser substituído por uma preocupação com os processos educativos e com as relações que fazem parte do meio escolar (Barbosa, 2012).

Assim, inicia-se um processo de consolidação desse campo de atuação, a partir da ressignificação de sua abordagem teórico-metodológica (Barbosa, \& Marinho-Araújo, 2010). Trata-se de superar a visão ingênua e ideologicamente comprometida da escola como instituição social neutra e repensar o seu papel, acolhendo os determinantes escolares do fracasso escolar, para além dos situados no aluno (Patto, 1981b). Para isso, a lógica de descentrar o foco do aluno convém considerar o aspecto intersubjetivo presente na aprendizagem e, portanto, também no fracasso da aprendizagem (Barbosa, \& Marinho-Araújo, 2010; Martins, 2003), de modo a questionar o funcionamento institucional que (re) produz o fracasso escolar (Cavalcante, \& Aquino, 2013). Nesse sentido, é necessário empregar novas metodologias que contemplem os fenômenos históricos que fazem parte da escola, encorajando os professores a se colocar de forma ativa no processo educacional e dando voz aos alunos. As metodologias devem ter o objetivo de estabelecer vínculos de confiança e criar possibilidades de escuta, tais como observação participante, entrevistas abertas, visitas domiciliares e participação em espaços lúdicos (Vokoy, \& Pedroza, 2005). Por isso, autores como Soares e Araujo (2010) e Nakamura e cols. (2008) valorizam intervenções realizadas com o corpo docente, no sentido de propor melhorias no processo de ensino e aprendizagem e diminuir o contingente de alunos que são diagnosticados como problema e o excesso de medicalização (Yamamoto, \& cols., 2013).

O psicólogo deve herdar da clínica a escuta, no sentido de acompanhar os fenômenos que fazem parte do campo escolar e utilizar, segundo Martins (2003), a abordagem multirreferencial, pois ela possibilita compreender a instituição, considerando sua complexidade, na medida em que aborda os fenômenos sob várias perspectivas de prática profissional, sem reduzi-las a um só olhar. Assim, rompe com a tradição positivista e cartesiana, que por muito tempo fez parte do fazer da Psicologia na Escola, para criar espaços de fala e escuta dos fenômenos escolares, através dos atores que fazem parte desse cenário. Na perspectiva defendida por Martins, o trabalho do psicólogo escolar se inscreve na ordem da intersubjetividade, do vivido, da experiência. Sendo assim, ele sugere a observação participante como uma técnica do psicólogo que é permeada pela escuta do não dito, a fim de compreender a instituição em sua complexidade, 
porque a complexidade não é intrínseca ao fenômeno, mas ao olhar que é colocado sobre ele.

Abandonar o viés clínico de tratar a queixa escolar como um fato isolado para ir ao encontro da compreensão da história escolar como processo (Dazzani, 2010; Guardia, 2005) é deslocar o olhar das estrelas para as suas interações, no contexto da constelação. Para tanto, o psicólogo deve estar atento à dinâmica institucional, capturando o fenômeno escolar como algo complexo e trabalhar numa perspectiva preventiva (Martins, 2003; Ulup, \& Barbosa, 2012; Silva, \& Mendes, 2012). Precisa criar um espaço para escutar as demandas da escola, criando formas de reflexão dentro na/da escola, considerando todos os envolvidos (Andrada, 2005).

\section{Considerações Finais e Perspectivas de Encontros entre a Psicologia e a Escola Contemporânea}

O presente artigo propôs-se a discutir os encontros e desencontros entre a Psicologia e a Escola, problematizando seus impasses e seus desafios. A história da Psicologia nos aponta para sua inserção na Escola desde um modelo médico/clínico, calcado numa concepção linear e reducionista do fracasso escolar. Houve, nesse sentido, um encontro entre a Psicologia e a Escola, na medida em que, comungando de uma mesma ideologia higienista, a ideia era de apartar os aptos dos não aptos para a aprendizagem. Assim, a Psicologia iniciou seu trabalho avaliando as habilidades do aluno e encaminhando os considerados não aptos para tratamento, conduzidos dentro ou fora do espaço escolar. Nessa perspectiva, a responsabilização do fracasso escolar estava centrada no aluno e na família, razão pela qual até os dias atuais encontramos o discurso da Educação impregnado de expressões tais como: aluno-problema, aluno preguiçoso, famílias desestruturadas. A entrada da Psicologia na escola respondeu a uma demanda de exclusão, na medida em que responsabilizava o aluno e, por extensão, a sua família pelo fracasso escolar. Ao psicólogo cabia avaliar, tratar e devolver o aluno desprovido dos problemas para a sala de aula. A Escola, por sua vez, permanecia protegida de quaisquer questionamentos sobre o seu papel educativo, sendo o aluno e sua família fonte da culpa pelo fracasso escolar. Na medida em que a Psicologia passa a criticar tal modelo, passa a se desenhar um abismo entre ela e a escola.

A superação desse modelo reducionista se deu marcada pelas contribuições de Maria Helena Souza Patto, a partir de uma crítica à ideologia adaptacionista. Tais contribuições geraram um reposicionamento da Psicologia no meio escolar, de modo a considerar outras implicações envolvidas no fenômeno do fracasso escolar e não só o aluno. Os impasses passaram a surgir na medida em que a lógica que ordenava o fazer docente era ainda a de considerar o aluno e sua família como problema, o que passou a gerar um mecanismo de tensionamentos entre a Psicologia e a Escola. Isso, pelo menos em parte, pode explicar a carência de profissionais da Psicologia que trabalham no campo escolar. No entanto, é importante também mencionar que a Psicologia parece ainda não ter conseguido definir o seu campo de atuação e seus métodos de trabalho na Escola. Isso, possivelmente, se deve à tradição clínica arraigada na matriz curricular, direcionando a formação do psicólogo ao fazer clínico, psicopatológico e individual. A prática em instituições compreende um campo permeado por inúmeros desafios que vão além do indivíduo em si. A partir dessa lógica, como implicar a instituição como um todo na (re)produção do fracasso escolar? Como acessar o corpo docente e implicá-lo no trabalho preventivo? Como diminuir os efeitos e a propagação do discurso social da medicalização? Tais questões apontam para o compromisso do psicólogo escolar, desde que se tenha o cuidado de não passar a tomar o professor como problema. A ideia é de que não há busca por "pessoas-problema" e sim a busca por comprometer a dinâmica dos envolvidos na produção do fracasso escolar para, então, intervir no campo de forças do qual faz parte o sistema educacional, com suas políticas e diretrizes, a escola, os professores, a equipe pedagógica e diretiva, o aluno e o social, em especial a família, e a história que marca todo o contexto em questão.

Apostamos nesse encontro, mas reconhecemos que ele não se dá sem que tenhamos que vencer inúmeros obstáculos e resistências, oriundos de nossa própria formação e da história da Escola e da Psicologia, que insiste em ser reeditada. Assim, estudos que levem em consideração a discussão sobre a história que se perpetua ao longo dos tempos são fundamentais para que essa temática ganhe força no campo da formação e da atuação profissional.

\section{Referências}

Andrada, E. G. C. (2005). Novos paradigmas na prática do psicólogo escolar. Psicologia: Reflexão e Crítica, 18(2), 196-199.

Angelucci, C. B., Kalmus, J., Paparelli, R., \& Patto, M. H. S. (2004). O estado da arte da pesquisa sobre o fracasso escolar (1991-2002): um estudo introdutório. Educação e Pesquisa, 30(1), 51-72.

Asbahr, F. S. F., Martins, E., \& Mazzolini, B. P. M. (2011). Psicologia, formação de psicólogos e a escola: desafios contemporâneos. Psicologia em Estudo, 16(1), 157-163.

Barbosa, D. R., \& Souza, M. P. R. (2012). Psicologia Educacional ou Escolar? Eis a questão. Psicologia Escolar e Educacional, 16(1), 163-173.

Barbosa, D. R. (2012). Contribuições para a construção da historiografia da Psicologia educacional e escolar no Brasil. Psicologia: Ciência e Profissão, 32(spe), 104-123.

Barbosa, R. M., \& Marinho-Araújo, C. M. (2010). Psicologia escolar no Brasil: considerações e reflexões históricas. Estudos de Psicologia (Campinas), 27(3), 393-402. 
Bassani, E., \& Pinel, H. (2011). Notas sobre a contribuição da obra de Maria Helena Souza Patto em um Programa de Pós-Graduação em Educação. Psicologia USP, 22(3), 551-568.

Cavalcante, L. A., \& Aquino, F. S. B. (2013). Ações de psicólogos escolares de João Pessoa sobre queixas escolares. Psicologia em Estudo, 18(2), 353-362.

Chagas, J. C., \& Pedroza, R. L. S. (2013). Psicologia escolar e gestão democrática: atuação em escolas públicas de Educação Infantil. Psicologia Escolar e Educacional, 17(1), 35-43.

Cunha, B.B.B., \& Betini, G. (2003). Psicologia e educação no contexto das secretarias municipais: algumas contribuições para novas práticas. Psicologia: Ciência e Profissão, 23(3), 42-49.

Dazzani, M. V. M. (2010). A psicologia escolar e a educação inclusiva: Uma leitura crítica. Psicologia: Ciência e Profissão, 30(2), 362-375.

Fontes, D. C., \& Lima, V. A. A. (2011). A escola segundo alunos do ensino médio de Porto Velho-RO. Psicologia Escolar e Educacional, 15(1), 71-79.

Giongo, C., \& Oliveira-Menegotto, L. M. (2010). (Des) Enlaces da psicologia escolar na rede pública de ensino. Psicologia USP, 21(4), 859-874.

Guardia, E. N. C. (2005). Aporte para uma hermenêutica em psicologia escolar. Psicologia: Ciência e Profissão, 25(2), 304-319.

Guzzo, R. S. L., Mezzalira, A. S. C., Moreira, A. P. G., Tizzei, R. P., \& Silva Neto, W. M. F. (2010). Psicologia e Educação no Brasil: uma visão da história e possibilidades nessa relação. Psicologia: Teoria e Pesquisa, 26, 131-141.

Guzzo, R. S. L., Mezzalira, A. S. C., \& Moreira, A. P. G. (2012). Psicólogo na rede pública de educação: embates dentro e fora da própria profissão. Psicologia Escolar e Educacional, 16(2), 329338.

Lessa, P. V., \& Facci, M. G. D. (2011). A atuação do psicólogo no ensino público do Estado do Paraná. Psicologia Escolar e Educacional, 15(1), 131-141.

Martins, J. B. (2003). A atuação do psicólogo escolar: multirreferencialidade, implicação e escuta clínica. Psicologia em Estudo, 8(2), 39-45.

Nakamura, M. S., Lima, V. A. A., Tada, I. N. C., \& Junqueira, M. H. R. (2008). Desvendando a queixa escolar: um estudo no Serviço de Psicologia da Universidade Federal de Rondônia. Psicologia Escolar e Educacional, 12(2), 423-429.

Patto, M. H. S. (Org.). (1981a). Introdução à psicologia escolar. São Paulo: T. A. Queiroz.

Patto, M. H. S. (1981b). Psicologia e ideologia: reflexões sobre a psicologia escolar. Tese de doutorado. Instituto de Psicologia, Universidade de São Paulo, São Paulo, SP.

Patto, M. H. S. (1987). Psicologia e ideologia: uma introdução crítica à psicologia escolar. São Paulo: T. A. Queiroz.

Ramos, C. (2011). A indignação dialética: paixão e resistência em Maria Helena Souza Patto. Psicologia USP, 22(3), 499-528.

Sant'Ana, I. M., Euzébios Filho, A., Lacerda Junior, F., \& Guzzo, R. S. L. (2009). Psicólogo e escola: a compreensão de estudantes do ensino fundamental sobre esta relação. Psicologia Escolar e Educacional, 13(1), 29-36.

Silva, A. M. , \& Mendes, E. G. (2012). Psicologia e inclusão escolar: novas possibilidades de intervir preventivamente sobre problemas comportamentais. Revista Brasileira de Educação Especial, 18(1), $53-70$.

Silva, S.M.C., Pedro, L.G., Silva, D., Rezende, D.,\& Barbosa, L.M. (2013). Estágio em psicologia escolar e arte: contribuições para a formação do Psicólogo. Psicologia: Ciência e Profissão, 33(4), 1014-1027

Soares, P. G., \& Araujo, C. M. M. (2010). Práticas emergentes em Psicologia Escolar: a mediação no desenvolvimento de competências dos educadores sociais. Psicologia Escolar e Educacional, 14(1), 45-54.

Tada, I. N. C., Sápia, I. P., \& Lima, V. A. A. (2010). Psicologia Escolar em Rondônia: formação e práticas. Psicologia Escolar e Educacional, 14(2), 333-340.

Tondin, C.F., Dedonatti, D.,\&Bonamigo, I.S. (2010). Psicologia Escolar na rede pública de educação dos municípios de Santa Catarina. Psicologia Escolar e Educacional, 14(1), 65-71.

Tuleski, S. C., Eidt, N. M., Menechinni, A. N., Silva, E. F., Sponchiado, D., \& Colchon, P. D. (2005). Voltando o olhar para o professor: a psicologia e pedagogia caminhando juntas. Revista do Departamento de Psicologia da UFF, 17(1), 129-137.

Ulup, L., \& Barbosa, R. B. (2012). A formação profissional e a ressignificação do papel do Psicólogo no cenário escolar: uma proposta de atuação - de estagiários a psicólogos escolares. Psicologia: Ciência e Profissão, 32(1), 250-263.

Valle, L. E. L. R. (2003). Psicologia escolar: um duplo desafio. Psicologia: Ciência e Profissão, 23(1), 22-29.

Vokoy, T., \& Pedroza, R. L. S. (2005). Psicologia Escolar em educação infantil: reflexões de uma atuação. Psicologia Escolar e Educacional, 9(1), 95-104.

Wanderer, A., \& Pedroza, R. L. S. (2010). Elaboração de projetos político-pedagógicos: reflexões acerca da atuação do psicólogo na escola. Psicologia Escolar e Educacional, 14(1), 121-129. 
Yamamoto, K., Santos, A. A. L., Galafassi, C., Pasqualini, M. G., \& Souza, M. P. R. (2013). Como atuam psicólogos na educação pública paulista? um estudo sobre suas práticas e concepções. Psicologia: Ciência e Profissão, 33(4), 794-807.

Recebido em: 15/04/2014

Reformulado em: 17/11/2014

Aprovado em: 03/06/2015

\section{Sobre as autoras}

Lisiane Machado de Oliveira-Menegotto (lisianeoliveira@feevale.br)

Psicóloga Clínica e Escolar. Mestre e Doutora em Psicologia do Desenvolvimento pela UFRGS. Docente do Curso de Psicologia e membro do corpo docente permanente do PPG em Diversidade Cultural e Inclusão Social da Universidade Feevale/RS.

Gabriela Prado da Fontoura (gabpradofont@gmail.com)

Graduada em Psicologia pela Universidade Feevale/RS. Graduada em Pedagogia pela Universidade Federal de Pelotas. Psicóloga no Programa Municipal de Educação Inclusiva (PMEI) e no Projeto Reintegrar do Município de Parobé.

Escola e Psicologia * Lisiane Machado de Oliveira-Menegotto \& Gabriela Prado da Fontoura 
